\section{De John Rawls a Norman Daniels: a justiça como equidade e a saúde}

Arimatea, Gustavo Guilherme Queiroz

Programa de Pós-graduação em Bioética, Universidade de Brasília.E-mail: keniaamaral_@hotmail.com

\section{Santos, Kênia Amaral Duarte dos}

Programa de Pós-graduação em Bioética, Universidade de Brasília

\section{Ramirez, Julie Catama}

Programa de Pós-graduação em Bioética, Universidade de Brasília

PALAVRAS-CHAVE: Bioética. Saúde Pública. Alocação de recursos. Equidade em saúde. Justiça social

A bioética tange a saúde pública na medida em que a relação médico-paciente, ou seja, dos prestadores de serviços em saúde e os consumidores deste serviço, tornou-se mais complexa(1). Além das questões de autonomia e respeito ao indivíduo, entraram em cena, juntamente com o Estado, novas formas de organização, como as comunidades e organizações não governamentais. Surgiram novos conflitos morais acerca dos custos de prevenção, diagnóstico, terapias e, consequentemente, as políticas públicas se tornaram atividades sociais cada vez mais relevantes para a coletividade (1). O presente trabalho tem por objetivo traçar um paralelo entre a teoria de justiça, criada por John Rawls, e a abordagem de justiça como equidade, desenvolvida por Norman Daniels a partir daquela teoria, inserindo questões de saúde no escopo da justiça social. Rawls desenvolveu uma teoria chamada Justiça como equidade, sendo atribuído a ele o mérito de ter feito renascer o interesse na filosofia política no último século(2). Sua obra caracterizou-se pela tentativa de acomodar em uma mesma teoria as ideias de que as pessoas devem ser livres e iguais e devem viver em uma sociedade justa. Esta ideia recebeu muita atenção ao longo das últimas décadas, incluindo inúmeras críticas. Entre elas, destaca-se o apontamento de que ele, deliberadamente, desconsiderou o efeito das doenças e das incapacidades sobre as vidas das pessoas quando elaborou sua teoria da justiça(3). Daniels, baseando-se naquele autor, inseriu as questões de saúde na discussão sobre justiça distributiva e acesso a bens sociais primários, pois entende que os princípios de justiça envolvem reconhecimento de que se deve estabelecer bases públicas para que sejam observados a dignidade e o respeito a todos(4). Reconhecido por seus trabalhos de investigação com enfoque no campo ético, para tomada de decisões em saúde, epistemologia, moral e justiça, aduz que as ciências sociais e a literatura em saúde pública podem ser boas ferramentas para entender melhor as desigualdades em saúde, já que elas não dependem exclusivamente da distribuição de renda, mas de muitos outros fatores(5). Metodologia: Adotou-se neste trabalho a metodologia de revisão bibliográfica, especificamente da revisão narrativa. Por meio de consulta a livros, sítios eletrônicos e periódicos buscou-se materiais produzidos acerca do tema justiça e equidade em saúde, em especial dos autores John Rawls e Norman Daniels, escolhidos como referência teórica. Conclusão: Ao contrário de Rawls, que preferiu silenciar sobre isto, Daniels entende que saúde é uma condição de acesso aos bens sociais primários, considera que as pessoas doentes estariam prejudicadas em seu funcionamento normal, tendo comprometidas as suas oportunidades dentro da sociedade. Ele entende que a teoria de Rawls, embora não responda a todas as questões sobre justiça e equidade em saúde, pela sua possibilidade de generalização permite sistematizar pensamentos a respeito de saúde pública, medicina, ciências sociais e filosofia política. A partir desta concepção, é possível utilizar a ideia de justiça como equidade no campo da bioética para discutir relevantes problemas morais de alocação de recursos e políticas públicas em saúde.

AGRADECIMENTOS: agradecemos ao coordenador e fundador da Cátedra Unesco de Bioética da Universidade de Brasília, professor doutor Volnei Garrafa e também aos nossos orientadores, os professores doutores Marcos Santos e Natan Monsores.

\section{REFERÊNCIAS}

[1] SCHRAMM FR, CASTIEL LD. Bioética e saúde pública. Cad Saúde Pública. 1999;15(Sup 1):4-5.

[2] NUSSBAUM M. The enduring significance of John Rawls. Chron High Educ. 2001;47(45):B7.

[3] LOVETT F. Uma teoria da justiça de John Rawls. Trad Vinicius Figueira Consult supervisão e revisão técnica Maria Carolina dos Santos Rocha Porto Alegre Penso. 2013;

[4] DANIELS N. Why Justice is good for our health. In: OPS/OMS, editor. Buenos Aires: Publication series 2002 of Regional Program on Bioethics; 2002. p. 37-52.

[5] DANIELS N. Just health: meeting health needs fairly. Cambridge University Press; 2007. 